\title{
How Multi-Step versus One-Step Preparation Method Affects the Physicochemical Properties and Transfection Efficiency of DNA/DODAB:MO Lipoplexes
}

\author{
J.P. Neves Silva ${ }^{1}$, A.C.N. Oliveira ${ }^{1,2}$, Marlene Lucio ${ }^{1}$, A.F.C. Gomes ${ }^{2,3}$, \\ M.E.C.D. Real Oliveira ${ }^{1,3,{ }^{*}}$ \\ ${ }^{1}$ Centre of Physics, University of Minho, Campus of Gualtar, 4710-057 Braga, Portugal \\ ${ }^{2}$ Centre of Molecular \& Environmental Biology CBMA, University of Minho, Campus of Gualtar, 4710-057 \\ Braga, Portugal \\ ${ }^{3}$ Nanodelivery I\&D in Bionanotecnology-LDA- Biology Department, Campus of Gualtar, 4710-057 Braga, \\ Portugal
}

\begin{abstract}
The consequences for the transfection efficiencies of different lipoplexes preparation methods, largely remain to be explored, but the knowledge of how different experimental approaches can affect the physicochemical properties and transfection efficiency is essential for a proper tailoring of transfection complexes to particular applications. Therefore, the influence of the number of mixing steps (one-step addition versus multi-step addition of liposomes to plasmid DNA (pDNA)) and lipoplex incubation temperature on the final physicochemical properties and transfection efficiency of pDNA/ Dioctadecyldimethylammonium Bromide (DODAB):1-monooleoyl-rac-glycerol (MO) complexes was studied in three distinct DODAB:MO molar ratios: 4:1, 2:1 and 1:1. Dynamic Light Scattering (DLS), Zeta $(\zeta)$ Potential, Ethidium Bromide ( $\mathrm{EtBr}$ ) exclusion assays were used to assess the formation, structure and destabilization of the lipoplexes, whereas in vitro transfection assays with pSV- $\beta$-gal plasmid DNA were performed to evaluate their
\end{abstract} transfection efficiency on the 293T mammalian cell line.

Results indicate that the morphology of pDNA/DODAB:MO complexes is dependent on the lipoplex preparation method, resulting in particles of distinct size, surface charge and membrane fluidity. These variations are visible during the complexation dynamics of pDNA and continue throughout the profile of pDNA release from pDNA/DODAB:MO lipoplexes upon incubation with Heparin (HEP), as well as in the in vitro transfection assays.

The stepwise addition of DODAB:MO vesicles to pDNA decreases the transfection efficiency of the lipoplexes, while the effect of the lipoplex preparation methods is dependent on the MO content.

Keywords: Monoolein-Based Lipoplexes, Lipoplex Preparation Method, Transfection.

\section{INTRODUCTION}

Cationic lipid complexes (lipoplexes) have several advantages as nucleic acid delivery systems over viral vectors, which are difficult to prepare, can be mutagenic and have low loading capacity [1-7]. There are several possible methods to prepare lipoplexes, and the implications of the different preparation procedures should be evaluated to reach better tailored gene nanocarriers.

The final transfection efficiency of the lipoplexes has been reported in the literature as dependent of the preparation strategies used in numerous aspects that include: (i) the type and proportions of main lipid and helper lipids chosen (e.g. changing lipoplex composition affects physicochemical properties, such as, size, surface charge and fluidity [8-25]); (ii) the type

*Address correspondence to this author at the CFUM, Centre of Physics, University of Minho, Campus of Gualtar, 4710-057 Braga, Portugal;

Tel: (+351) 253604 325; Fax: (+351) 253678 981;

E-mail: beta@fisica.uminho.pt of aggregates formed (e.g. in comparison to multilamellar vesicles, lowest molecular weighted small unilamellar vesicles require more aggregates to complex the same amount of DNA) [26]; (iii) the chosen addition procedure (e. g. lipoplexes prepared by a titration procedure where cationic liposomes were added stepwise to DNA led to smaller and more fluid lipoplexes than the lipoplexes obtained by the instant mixing procedure $[27,28]$ ); (iv) the order by which DNA and liposomes are mixed (e.g. lipoplexes resulting from the addition of DNA to cationic vesicles had bigger sizes and higher negative charge densities, thus presenting lower cellular binding and transfection efficiencies than lipoplexes obtained from the addition of cationic vesicles to DNA [29]); (v) the ionic strength (e.g. altering ionic strength demonstrated effects in the aggregation, complexation and transfection efficiency $[30,31])$.

Given the reported impact that the optimization of experimental procedures (such as the vesicle preparation method or the stepwise addition of cationic liposomes to DNA) may have on the lipoplex 
transfection efficiency we have decided to study the influence of the number of mixing steps (one-step addition versus multi-step addition of liposome vesicles to $\mathrm{pDNA}$ ) on the final physicochemical properties and transfection efficiency of a recently described lipoplex system (pDNA/DODAB:MO complexes) in three distinct DODAB:MO molar ratios: 4:1, 2:1 and 1:1. The physicochemical properties of the lipoplexes (size, charge and structure) prepared by the different methods were studied by Dynamic and Electrophoretic Light Scattering (DLS and ELS) and Cryo-Transmission Electron Microscopy (Cryo-TEM). Ethidium Bromide $(\mathrm{EtBr})$ exclusion fluorescence assays and electrophoretic mobility were used to study the complexation dynamics of pDNA after addition of DODAB:MO vesicles, and also the extent of pDNA release from $\mathrm{pDNA} / \mathrm{DODAB}: M O$ systems upon incubation with Heparin (HEP) or Fetal Bovine Serum (FBS). Finally, in vitro transfection assays were performed in 293T human cell line using the pSV- $\beta$-gal plasmid, in order to investigate the correlation between these different lipoplex preparation methods and the final lipofection efficiency.

\section{MATERIALS AND METHODS}

\subsection{Materials}

MO, Dulbecco's Modified Eagle's Medium (DMEM), penicillin/streptomycin/amphotericin B (10 000 units/10 $\mathrm{mg} / 25 \mu \mathrm{g}$ per $\mathrm{mL}$ ) solution, agarose gel, and heparin from the porcine intestinal mucosa were purchased from Sigma-Aldrich. DODAB was purchased from Tokyo Kasei (Japan). Opti-MEM I Reduced Serum Medium was purchased from Gibco (UK). The intercalating probe EtBr was purchased from Molecular Probes (UK). FBS was purchased from Invitrogen. The Wizard Plus Midipreps DNA Purification System and $\beta$ Galactosidase Enzyme Assay System with Reporter Lysis Buffer were purchased from Promega (USA). GelRed $^{\mathrm{TM}}$ Nucleic Acid Gel Stain was purchased from Biotium (CA).

\subsection{Plasmid DNA Preparation}

pSV- $\beta$-gal plasmid DNA was amplified with Escherichia coli DHB4 competent cells. The pDNA was isolated and purified with the Wizard $®$ Plus Midipreps DNA Purification System Extraction Kit. After purification, pDNA was ressuspended in ultra-pure water at a nucleotidic phosphate group concentration of $0.5 \mu \mathrm{g} \mathrm{LL}^{-1}$ determined by absorption at $260 \mathrm{~nm}$ [32] with NanoDrop ND1000 Spectrophotometer. pDNA purity was also verified by determining the ratio of absorbance at $260 / 280 \mathrm{~nm}$ with the same equipment.

\subsection{Liposomes Preparation}

Defined volumes from the stock solutions of DODAB and $\mathrm{MO}$ in ethanol $(20 \mathrm{mM})$ were injected under vigorous vortexing to an aqueous buffer solution of Tris- $\mathrm{HCl}(30 \mathrm{mM})$ at $70{ }^{\circ} \mathrm{C}$, so that the final lipid concentration ([DODAB + MO]) was $1 \mathrm{mM}$ and the different DODAB:MO molar ratios $(4: 1,2: 1$, and 1:1) were obtained.

\subsection{Lipoplexes Preparation}

pDNA/DODAB:MO (4:1, 2:1 and 1:1) lipoplexes were prepared by incubating pSV- $\beta$-gal plasmid DNA and DODAB:MO $(4: 1,2.1$ and 1:1) vesicles in OptiMEM I Reduced Serum medium at CRs (+/-) 0.0, 0.25, $0.75,1.0,1.5,2.0$ and 4.0 , under 5-30 min stirring.

The CR (+/-) is an indicator of balance between positive charges (given by the concentration of ammonium groups present in DODAB) and negative charges (given by the concentration of nucleotidic phosphate groups in pDNA, which corresponds to nucleotide concentration) [12]:

$$
C R(+/-)=\frac{[+]}{[-]}=\frac{[\text { Ammonium groups from DODAB }]}{[\text { Phosphate groups from DNA }]}
$$

The different CRs (+/-) prepared resulted from the addition of adequate volumes of cationic vesicles to the pDNA solution for all the molar ratios studied. The incubation procedure previously described was performed in two distinct manners: one-step addition of cationic vesicles to pDNA and multi-step addition of cationic vesicles to pDNA.

\subsection{Dynamic Light Scattering (DLS) Assays}

pDNA/DODAB:MO (4:1, 2:1, and 1:1) lipoplexes at CRs (+/-) $0.25,0.5,0.75,1.0,1.5,2.0$ and 4.0 were prepared by different methods and placed in disposable polystyrene cuvettes for DLS measurements in a Malvern ZetaSizer Nano ZS particle analyzer. Malvern Dispersion Technology Software (DTS) was used with multiple narrow mode (high resolution) data processing, and mean diameter $(\mathrm{nm})$ average and error values were considered.

\subsection{Electrophoretic Light Scattering (ELS) Assays}

pDNA/DODAB:MO (4:1, 2:1, and 1.1) lipoplexes at CRs (+/-) $0.25,0.5,0.75,1.0,1.5,2.0$ and 4.0 were 
prepared by different methods and placed in universal dip cells for $\zeta$-potential measurements by ELS in a Malvern ZetaSizer Nano ZS particle analyzer. Malvern Dispersion Technology Software (DTS) was used with monomodal mode data processing, and $\zeta$-potential $(\mathrm{mV})$ average and error values were considered.

\subsection{Ethidium Bromide Exclusion Fluorescence Assays}

Ethidium bromide exclusion assay is a commonly used technique to access the lipoplex formation by conjugation of polycationic lipossomes and anionic nucleic acids. The principle behind this assay is that ethidium bromide $(\mathrm{EtBr})$ is a fluorescent probe that, when excited at $510 \mathrm{~nm}$ in an aqueous solution, gives a weak fluorescence emission; when $\mathrm{EtBr}$ intercalates into the DNA helix, the fluorescence emission increases. However, when the polycationic lipossomes are conjugated with DNA, EtBr molecules are displaced from the DNA strand to the water media, and a reduction in the fluorescence emission is seen [13].

In this assay, lipoplexes were prepared by adding the desired volume of cationic liposome suspensions (1 $\mathrm{mM}$ ) to $2.5 \mathrm{~mL}$ of pSV- $\beta$-gal plasmid DNA solution ( 20 $\mu \mathrm{g} \mathrm{mL} \mathrm{L}^{-1}$ ) diluted in Opti-MEM I medium. EtBr was added to the lipoplexes at a concentration $\left(7.0 \times 10^{-6} \mathrm{M}\right)$ six times lower than that of the pDNA, to assure that the decrease in the probe fluorescence is directly proportional to the amount of cationic lipid at a given nucleotide base concentration [33]. Suitable control experiments were performed (solution of DNA + EtBr, and solution of cationic vesicles $+\mathrm{EtBr}$ ).

The steady-state fluorescence measurements were performed in a Horiba Jobin Yvon Spex Fluorolog-3 spectrofluorimeter for each CR (+/-) analyzed, after a 5 min agitation period with a magnetic stirrer. The fluorescence intensities were determined at $\lambda_{\text {exc }}=510$ $\mathrm{nm}$, because this wavelength is known to be an isosbestic point for EtBr/DNA solutions [34]. All emission spectra were integrated, and the ratio of the areas was determined, after subtraction of the solvent background. Each fluorescence emission spectrum was fitted to a sum of two log-normal functions [35], corresponding to different environment states (DNA and $\mathrm{H}_{2} \mathrm{O}$ ). Assuming that the quantum yield of $\mathrm{EtBr}$ in the lipoplex remains constant for all the CRs $(+/-)$, the percentage of complexed pDNA $(\alpha)$ at $C R(+/-) x$ can be determined from the spectral decomposition previously made [35]:

$$
\alpha_{\text {at } C . R .(+/-) x}=\left(\frac{\int I_{F \text { at } C . R .(+/-) 0.0}^{D N A}-\int I_{F \text { at } C . R .(+/-) x}^{25^{\circ} C}}{\int I_{F \text { at } C . R .(+/-) 0.0}^{D N A}}\right) \times 100
$$

Lipoplex stability was also analyzed after addition of endogenous glycosaminoglycan (GAG) negative polyelectrolytes (heparin) to the pre-formed lipid/pDNA complexes at CR (+/-) 4.0 and $37^{\circ} \mathrm{C}$. EtBr emission spectra were recorded for each heparin addition until $\mathrm{CR}(+/-)$ reverted to $0.125([$ Heparin $]=278 \mu \mathrm{M})$.

\subsection{Cell Transfection Assays}

The 293T human cell line was cultured in DMEM medium supplemented with $10 \%(\mathrm{v} / \mathrm{v})$ heat-inactivated FBS and penicillin/streptomycin/amphotericin B (10 000 units $/ 10 \mathrm{mg} / 25 \mathrm{\mu g}$ per $\mathrm{mL}$ ) solution. Cells were subcultured every two days in order to maintain subconfluency.

For cell transfection assays, 293T cells were seeded into 24 -wells plates $12-16 \mathrm{~h}$ prior to the addition of the different lipoplex solutions. Individual $100 \mu \mathrm{L}$ lipoplex solutions were prepared by one-step/multi-step addition of adequate volumes of $1 \mathrm{mM}$ liposome solutions (DODAB:MO $(4: 1,2: 1$ or $1: 1)$ to Opti-MEM I medium containing $0.5 \mu \mathrm{g}$ of pDNA. The solutions were left to stabilize for $30 \mathrm{~min}$ under constant stirring and finally added to each well after culture medium replacement. Transfection of pDNA was also carried out with the Lipofectamine ${ }^{\text {TM }}$ LTX Reagent according to manufacturer's instructions.

$\beta$-galactosidase activity was evaluated $48 \mathrm{~h}$ later with the $\beta$-Galactosidase Enzyme Assay System with Reporter Lysis Buffer, according to standard protocol. Data from three independent experiments were log transformed to obtain a normal distribution and oneway analysis of variance statistical test (ANOVA) was applied to identify differences across the various groups, followed by a Turkey's post test. $\mathrm{P}<0.05$ was considered to be statistically significant.

\section{RESULTS \& DISCUSSION}

In excess of water and above the main phase transition temperature $\left(T_{m}\right)$, the synthetic cationic surfactant DODAB tends to form lamellar aggregates $\left(\mathrm{T}_{\mathrm{m}}=45^{\circ} \mathrm{C}[36]\right)$, whereas the amphiphilic neutral lipid of natural origin $\mathrm{MO}\left(\mathrm{T}_{\mathrm{m}}=35^{\circ} \mathrm{C}\right.$ [37]) forms inverted aggregates with negative curvature [38]. The conjugation of these two different surfactants results in a structurally rich polymorphic system, highly 
dependent on physicochemical parameters such as temperature and DODAB:MO molar ratios, as recently reported [39]. Moreover, it was found that the addition of cationic liposomes to pDNA leads to a dual-lipoplex phase diagram, with prevalence of lamellar structures at DODAB molar fractions above 0.5 and inverted bicontinuous cubic mesophases at DODAB molar fractions below 0.5 [40]. The fluidizing effect of $M O$ improves the complexation efficiency of pDNA, accelerating lipoplex formation and enhancing the transfection efficiency in 293T cell line [40-42]. Additionally, it has also been shown that MO promotes the existence of inverted bicontinuous cubic mesophases, resulting in non-lamellar aggregates that are more resistant to destabilization by proteoglycans [40].

All these evidences suggest that pDNA/DODAB:MO lipoplexes are strongly affected by the same physicochemical parameters that influence DODAB:MO lipid phase equilibrium, with possible consequences for the lipofection success of the system. Therefore, we have decided to study the influence of lipoplex preparation method (one-step addition, OS, versus multi-step addition, MS, of liposomes to pDNA) on the final physicochemical properties and transfection efficiency of pDNA/DODAB:MO systems at DODAB:MO molar ratios: $4: 1,2: 1$ and $1: 1$.

\subsection{Influence of the Lipoplex Preparation Method on pDNA Complexation, Lipoplex Size and Lipoplex Surface Charge}

$\mathrm{EtBr}$ is a fluorescent probe that is excited at $510 \mathrm{~nm}$ and emits at: $610 \mathrm{~nm}$, when it is intercalated in DNA (DNA band); or at $630 \mathrm{~nm}$ with low $\Phi_{\mathrm{F}}$, when DNA suffers condensation releasing the probe to the aqueous media $\left(\mathrm{H}_{2} \mathrm{O}\right.$ band). By fitting each $\mathrm{EtBr}$ fluorescence emission spectrum into a sum of 2 lognormal functions corresponding to the different environment states (DNA and $\mathrm{H}_{2} \mathrm{O}$ ), it is possible to follow the pDNA condensation by the cationic vesicles (Supplementary Material 1). EtBr exclusion assays
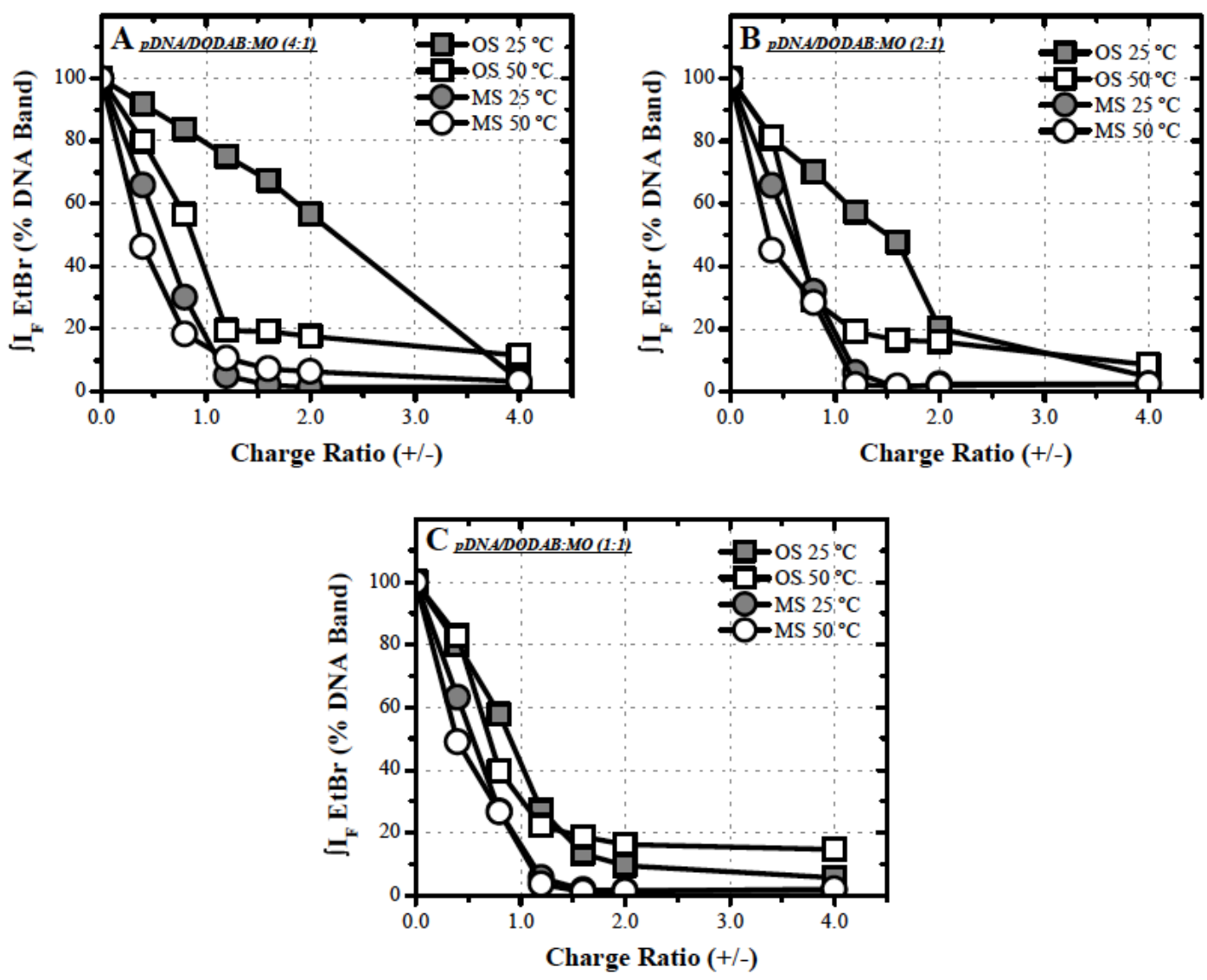

Figure 1: pDNA complexation efficiency upon addition of increasing amounts of different DODAB:MO formulations (4:1, 2:1 and 1:1). Variation of the decomposed fluorescence intensities of $\mathrm{EtBr}$ in pDNA band for different pDNA/DODAB:MO systems prepared by different lipoplex preparation methods (OS $25^{\circ} \mathrm{C}$-gray square, OS $50{ }^{\circ} \mathrm{C}$-white square, MS $25^{\circ} \mathrm{C}-$ gray circle, MS $50^{\circ} \mathrm{C}$ - white circle) at different CRs (+/-). A - pDNA complexation for pDNA/DODAB:MO (4:1); B - pDNA complexation for pDNA/DODAB:MO (2:1); and C - pDNA complexation for pDNA/DODAB:MO (1:1). 
were used to monitor pDNA complexation by DODAB:MO liposomes. Figure 1 shows the pDNA complexation efficiency upon addition of DODAB:MO (4:1; $2: 1$ and $1: 1)$, at different lipid phases $\left(25^{\circ} \mathrm{C}-\mathrm{L}_{\beta}\right.$ and $50{ }^{\circ} \mathrm{C}-\mathrm{L}_{\alpha}$ ) and using a different number of mixing steps (OS versus MS).

The effect of the temperature or the number of mixing steps is more pronounced for lipoplexes with higher DODAB content $(4: 1>2: 1>1: 1)$. The decrease in $\mathrm{EtBr}$ fluorescence emission indicates that lipoplexes are formed at lower $C R s$ for liposomes richer in DODAB (DODAB:MO (4:1 and 2:1) (Figures 1A and 1B).

Lipoplex formation is a highly dynamic event involving two main steps: first, the electrostatic binding of DNA to the liposome surface (DNA coating) and then, the fusion and rearrangement of liposomes to produce the final aggregates [43]. Since the dominant factor of lipoplex formation is the DNA coating step [43], and different DNA complexation dynamics were found on Figure 1, it can be inferred that the OS and MS procedures will mainly affect the DNA coating step when lipoplexes are being formed. In MS procedure, the stepwise addition of cationic aggregates to pDNA makes the condensation process more cooperative and sequenced, facilitating lipoplexes formation, that is practically not affected by the temperature. This is in agreement with other reported MS procedures [28], where the multiple interactions of one component with the other fastened the nucleation process, thus turning the lipoplex formation into a highly cooperative step. Contrastingly, when the OS procedure is used, the condensation of pDNA is slower when compared to MS procedure at the same temperature, because the complexation is neither cooperatively facilitated, nor sequenced from a previously metastable intermediate structure. Furthermore, the OS mixing procedure is temperature dependent. Therefore, as observed through $\mathrm{EtBr}$ fluorescence emission decrease on Figure $1 \mathrm{~A}$ and $1 \mathrm{~B}$, the formation of lipoplexes by the OS procedure occurs at lower CRs for higher temperatures (higher than $\mathrm{T}_{\mathrm{m}}$ of the liposomes). This can also be inferred by the smaller isoelectric points obtained at higher temperatures (isoelectric point occurs at CR (+/-) 1.5 and CR (+/-) 1.0, for 25 and 50 ${ }^{\circ} \mathrm{C}$, respectively) particularly evident in the case of lipoplex prepared by one-step preparation method (OS).

Figure 1C shows that the differences between OS and MS procedures, as well as temperature, are attenuated, and the lipoplex formation follows a similar dynamics for all the conditions, being practically complete at $C R(+/-) \geq 2$. This result can be explained by the presence of a high content of the helper lipid $\mathrm{MO}$, which has a fluidizing effect on DODAB:MO liposome bilayers, promoting the lipoplex assembly and increasing the pDNA cooperative collapse.

The effect of the different lipoplex preparation methods on pDNA condensation efficiency was further evaluated by DLS. Results are shown in Figure 2 .

Upon liposomal addition to pDNA and, consequently, after the DNA coating of the liposomes, two processes occur for the formation of cationic lipoplexes: the DNA-induced membrane fusion and the liposomes-induced cooperative DNA collapse [43]. Both processes can be observed on Figure 2: the peaks correspond to the big structures obtained during lipoplex assembly driven by DNA-induced membrane fusion, and the decrease in size observed after this point corresponds to the latter DNA collapse process. This is a key event, and consists on the entrapment of DNA molecules between the lipid lamellas, in clusters of condensed structures. These condensed structures correspond to the smaller sizes reached during the lipoplex assembly, and are seen in Figure $\mathbf{2}$ for higher CRs (+/-).

When the OS procedure is used to prepare pDNA/DODAB:MO lipoplexes, at higher CRs (+/-), the rapid mixing caused by the excess of cationic vesicles leads to instant vesicle-vesicle adhesion and rupture, originating highly organized lipoplexes with big particle sizes [45]. When the temperature is increased from 25 to $50^{\circ} \mathrm{C}$, the fluidity of the liposomes is enhanced, which dictates a higher compaction level of pDNA, forming lipoplexes which are up to $1 / 4$ smaller than the lipoplexes prepared at $25{ }^{\circ} \mathrm{C}$. This result was also observed for cryo-TEM imaging studies [46].

The MS addition of DODAB:MO cationic vesicles to pDNA produces opposite effects on the final size of the lipoplexes: at $25{ }^{\circ} \mathrm{C}$ the size of the lipoplexes decreases and at $50{ }^{\circ} \mathrm{C}$ the size of the lipoplexes increases, regardless of the MO content. The MS titration method implies that the component that is being titrated (pDNA) is in excess until the last stages of the DODAB:MO liposomes addition (assuming formation of a final complex that is near surface charge neutrality) therefore, pDNA coated vesicles with low diameters are formed, that persist metastably at a lower CR (+/-) range (Figure 2) [45]. Nevertheless, 

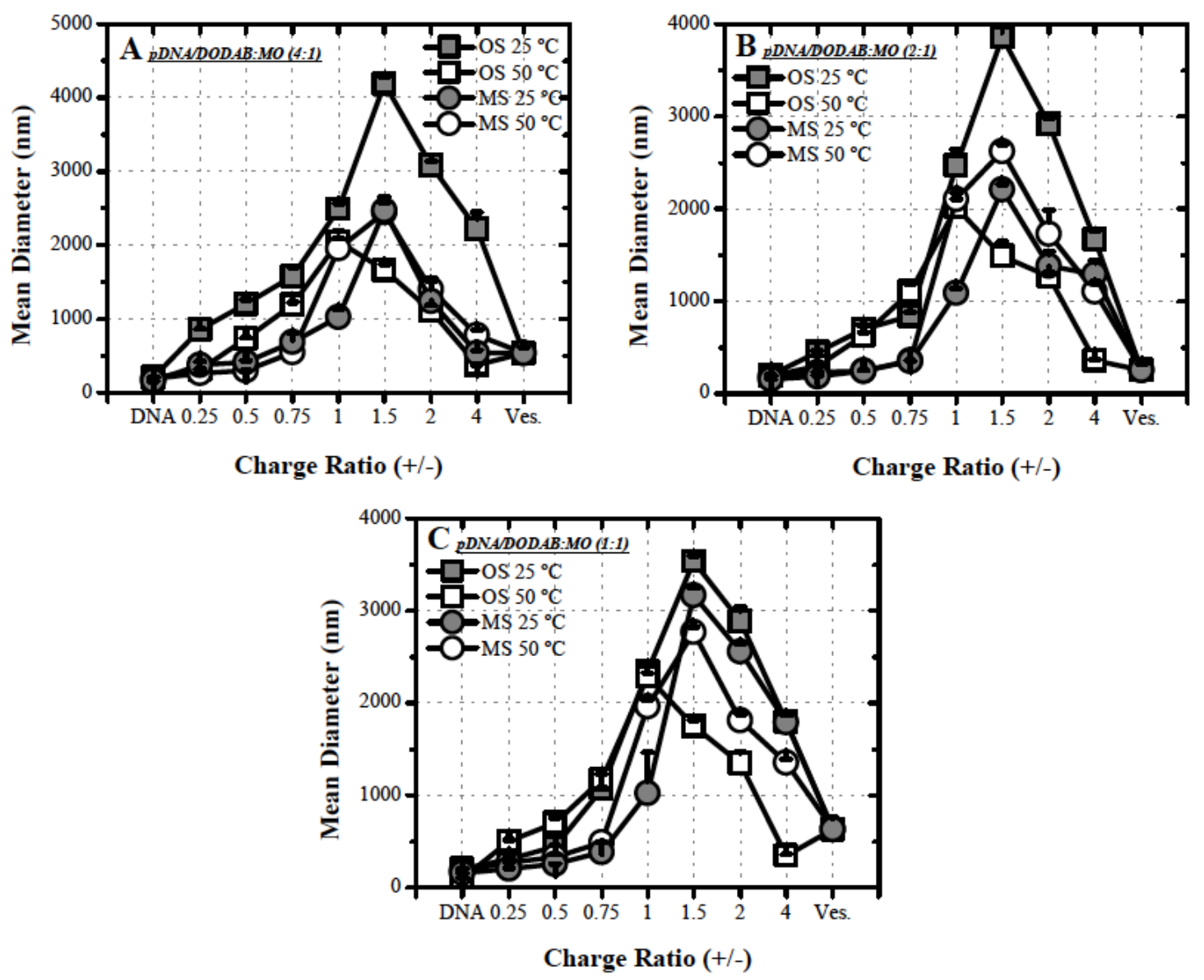

Figure 2: Mean diameter $(\mathrm{nm})$ of free $\mathrm{pDNA}$, free DODAB:MO vesicles and pDNA/DODAB:MO lipoplexes prepared by different methods (OS $25^{\circ} \mathrm{C}$-gray square, OS $50^{\circ} \mathrm{C}$-white square, MS $25^{\circ} \mathrm{C}$ - gray circle, MS $50^{\circ} \mathrm{C}$ - white circle) at different CRs (+/-). A - pDNA/DODAB:MO (4:1); B - pDNA/DODAB:MO (2:1); and C - pDNA/DODAB:MO (1:1).

while at $25{ }^{\circ} \mathrm{C}$ these metastable lipoplexes persist, at $50{ }^{\circ} \mathrm{C}$ the fluidity increases and the extra lipid mobility leads to changes on the lipid bilayers mean curvature. As a result, lipoplex fusion occurs, causing an increase of lipoplexes size (Figure 2).

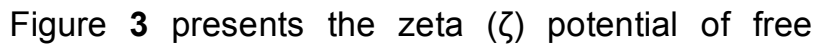
PDNA, free DODAB:MO vesicles and pDNA/DODAB:MO lipoplexes prepared by different methods (OS $25^{\circ} \mathrm{C}$, OS $50^{\circ} \mathrm{C}$, MS $25^{\circ} \mathrm{C}$, MS $50^{\circ} \mathrm{C}$ ) and at different CRs (+/-).

Preparation of pDNA/DODAB:MO at $50{ }^{\circ} \mathrm{C}$ forms lipoplexes that are clearly more positively charged than lipoplexes prepared at $25{ }^{\circ} \mathrm{C}$, irrespective of the $\mathrm{MO}$ content or the mixing steps employed (OS versus MS). As previously explained, raising the temperature has an impact in the liposomes fluidity, improving their binding efficiency to pDNA. However, after the liposomes have been covered by DNA, they fuse and suffer reorganization to assure the best stability of the lipoplex formed. This restructuring consists on the distribution of DODAB lamellar structures around the
DNA/lipid aggregates, to avoid lipoplex disaggregation and to maximize favorable interactions with the surrounding water molecules. This restructuring was also reported in other lipoplexes containing DNA [47] and is facilitated by the temperature increase. At $25^{\circ} \mathrm{C}$ and at CR (+/-) 4.0, MS addition of cationic vesicles to pDNA produces metastable lipoplexes that are not fully covered of pDNA, presenting lower zeta potentials. Contrastingly, the lipoplexes formed by OS are highly organized structures that protect the pDNA molecules, leading to higher zeta potentials (Figure 3 ).

\subsection{Modulation of pDNA Release by the Lipoplex Preparation Method and MO Content}

The EtBr fluorescence exclusion assay used to study pDNA complexation can also be also used to evaluate the extent of pDNA release from lipoplexes. Figure 4 shows pDNA release upon addition of the negative polyelectrolyte heparin to lipoplexes, based on the fact that the reintercalation of $\mathrm{EtBr}$ on the newly released pDNA will enhance the pDNA emission band. 

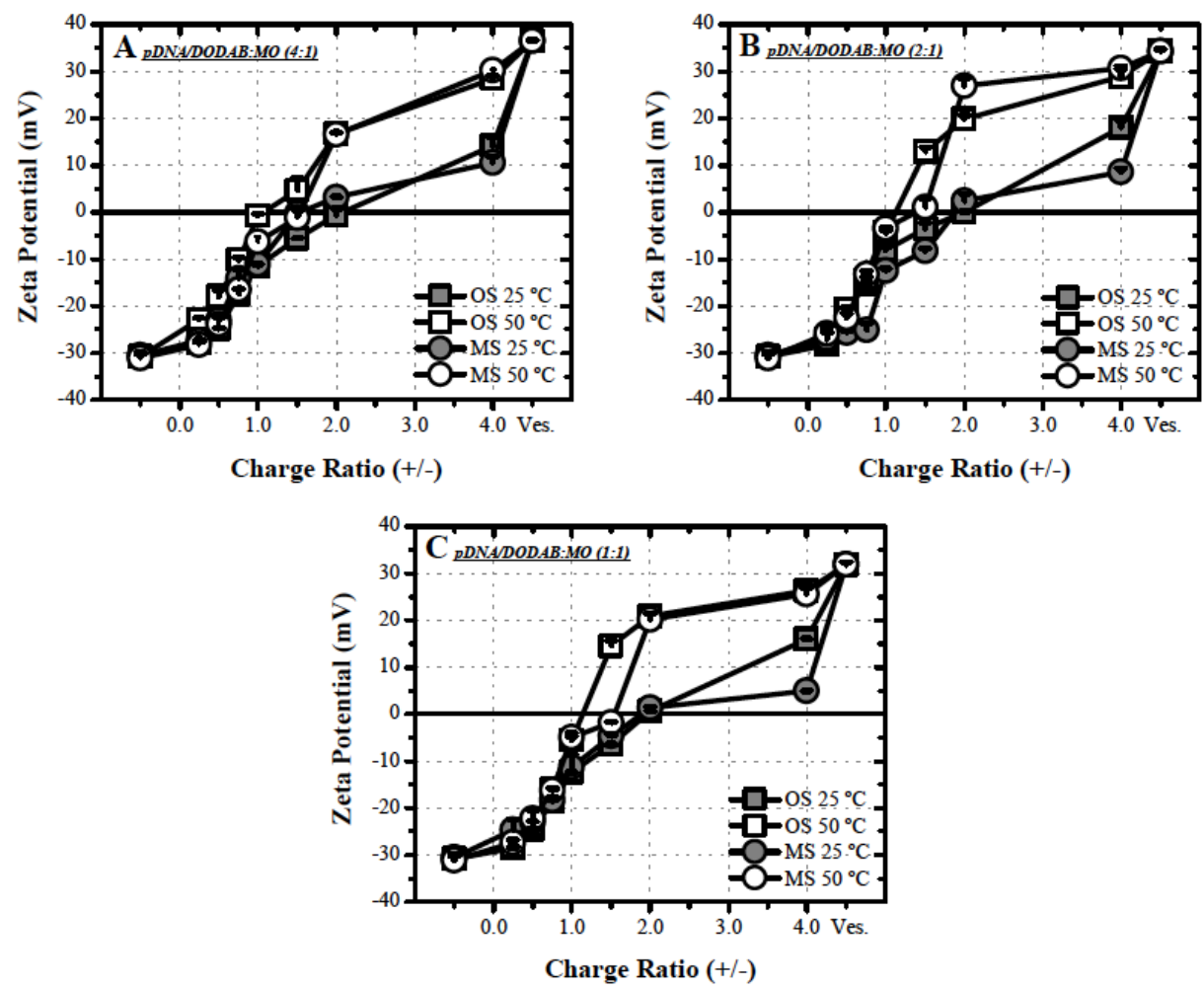

Figure 3: Zeta $(\zeta)$ potential $(\mathrm{mV})$ of free pDNA, free DODAB:MO vesicles and pDNA/DODAB:MO lipoplexes prepared by different methods (OS $25^{\circ} \mathrm{C}$-gray square, OS $50^{\circ} \mathrm{C}$-white square, MS $25^{\circ} \mathrm{C}$ - gray circle, MS $50{ }^{\circ} \mathrm{C}$ - white circle) at different CRs (+/-). A - pDNA/DODAB:MO (4:1); B - pDNA/DODAB:MO (2:1); and C - pDNA/DODAB:MO (1:1).
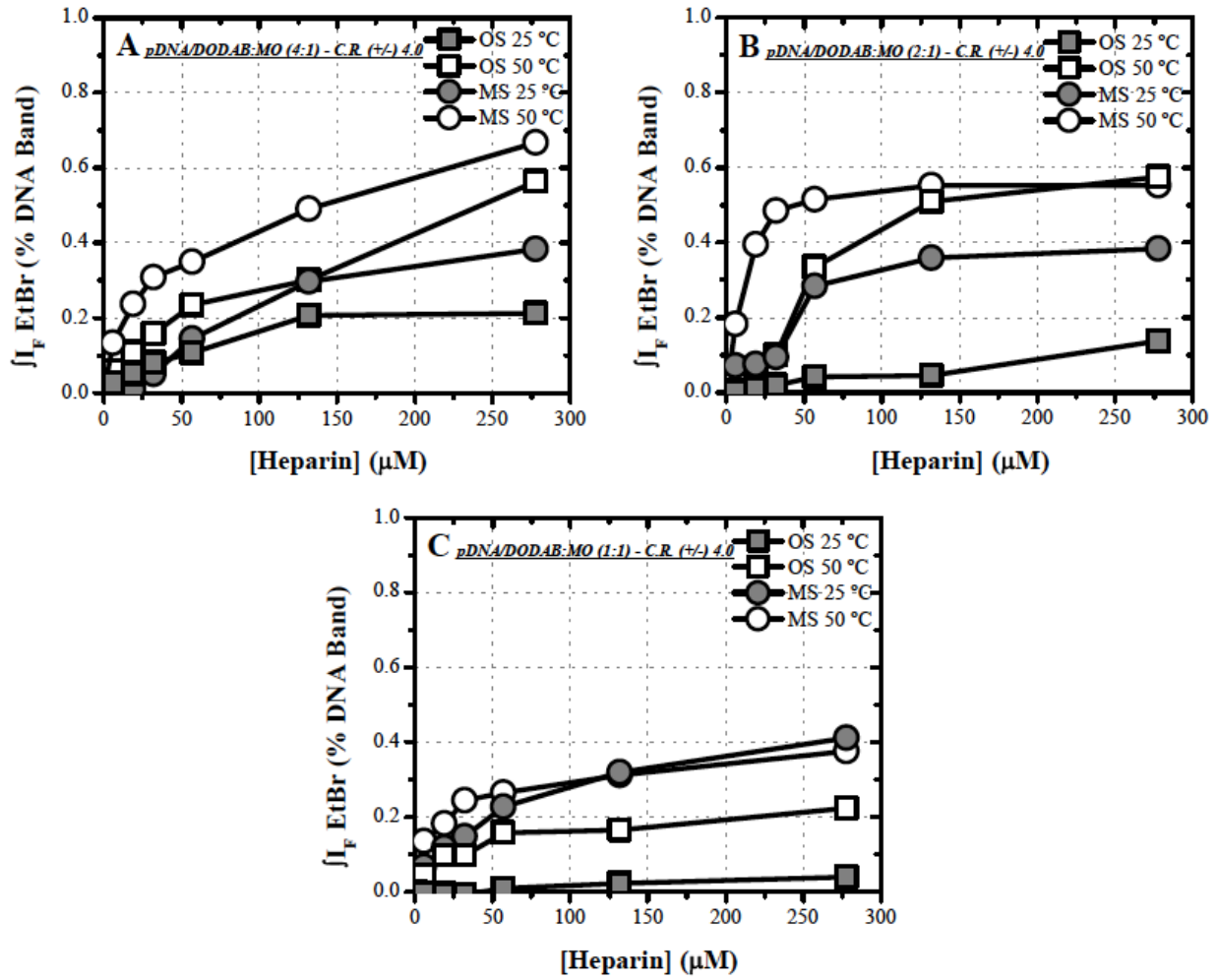

Figure 4: pDNA release from pDNA/DODAB:MO lipoplexes upon addition of increasing amounts of heparin (HEP). Variation of the decomposed fluorescence intensities of $\mathrm{EtBr}$ in pDNA band for different pDNA/DODAB:MO lipoplexes prepared by different methods (OS $25^{\circ} \mathrm{C}$-gray square, OS $50^{\circ} \mathrm{C}$-white square, MS $25^{\circ} \mathrm{C}$ - gray circle, MS $50^{\circ} \mathrm{C}-$ white circle) at different CRs (+/-). A - pDNA release for pDNA/DODAB:MO (4:1); $\mathbf{B}$ - pDNA release for pDNA/DODAB:MO (2:1); and C - pDNA release for pDNA/DODAB:MO (1:1). 
One-step $\left(25^{\circ} \mathrm{C}\right)$

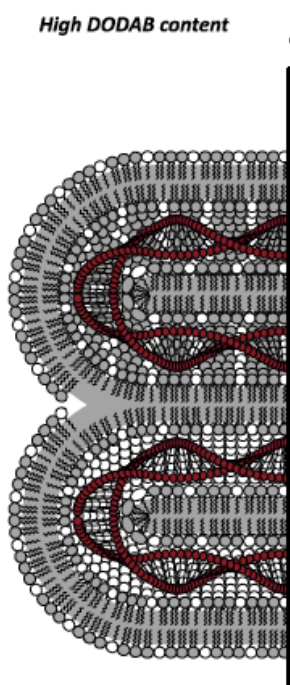

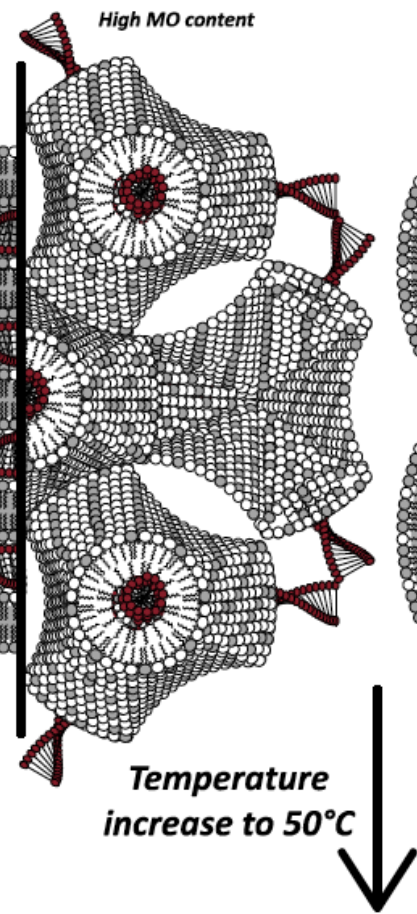

One-step/Multi-step $\left(50^{\circ} \mathrm{C}\right)$
Multi-step $\left(25^{\circ} \mathrm{C}\right)$

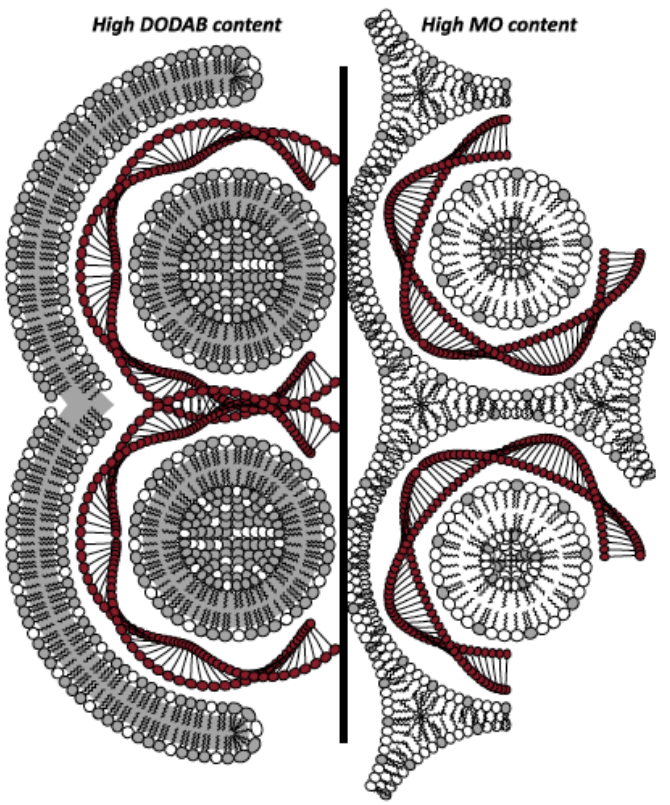

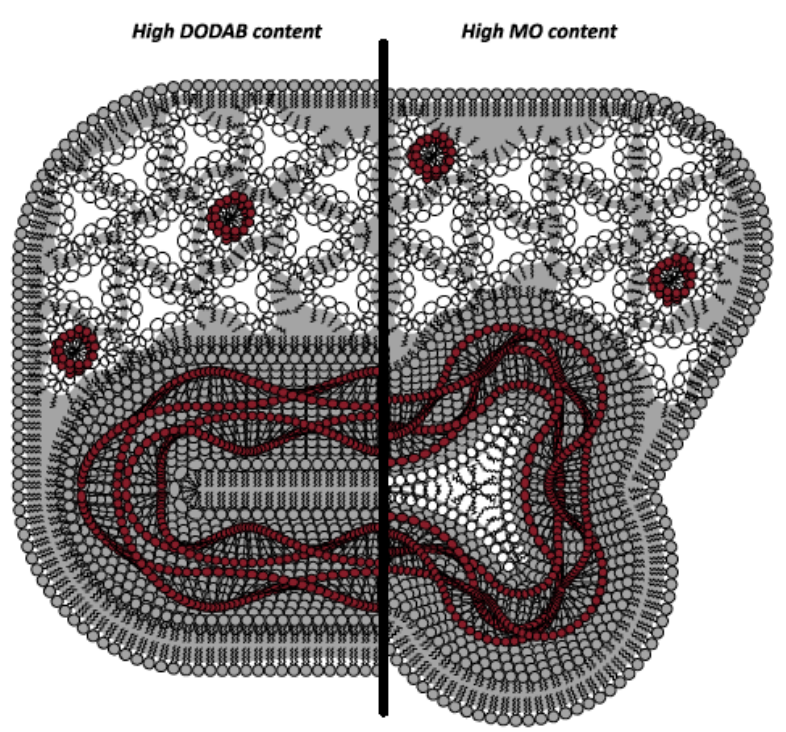

Figure 5: Theoretical model of lipid/DNA structural organization in pDNA/DODAB:MO lipoplexes at different DODAB:MO contents ("high DODAB content" refers to $(4: 1)$ and $(2: 1)$ formulations and "high MO content" to (1:1) and prepared by the different methods in study: OS $\left(25^{\circ} \mathrm{C}\right)$, OS $\left(50^{\circ} \mathrm{C}\right)$, MS $\left(25^{\circ} \mathrm{C}\right)$ and MS $\left(50^{\circ} \mathrm{C}\right)$. Double-tailed molecule with grey-headgroup represents $\mathrm{DODAB}$ and single-tailed molecule with white-headgroup represents $\mathrm{MO}$. Grey-coloured regions represent $\mathrm{DODAB}$ rich-domains and white-coloured regions represent $\mathrm{MO}$ rich-domains.

Heparin induces very different patterns of pDNA release from lipoplexes, according to the different DODAB:MO formulations. Upon the final addition of heparin, DODAB enriched lipoplexes (pDNA/DODAB: MO (4:1 and 2:1, Figure $4 A$ and $4 B$, respectively)) release higher pDNA amounts when compared to $M O$ enriched lipoplexes (pDNA/DODAB:MO (1:1) (Figure
4C)), reinforcing the already reported protective effect of MO on lipoplex stabilization [40]. In general, the lipoplex destabilization seems to be less dependent on the addition procedure (MS or OS) and more related with the lipoplex surface potential. In fact, if the lipoplex surface charge is highly positive, then the interactions with the negatively charged proteoglycans will be 
promoted, leading to a more efficient pDNA release. For the same reason, pDNA/DODAB:MO lipoplexes prepared at $50{ }^{\circ} \mathrm{C}$ are associated with a higher percentage of pDNA release, once the lipoplex surface charge is more positive at this temperature due to the distribution of the DODAB lipids in lamellar structures, protecting the pDNA inside the lipoplex.

Additionally, at a given temperature $\left(25\right.$ or $\left.50^{\circ} \mathrm{C}\right)$, the pDNA release is higher for lipoplexes prepared by MS procedure. This is consistent with the DLS (Figure 2) and zeta potential (Figure 3) results and might be explained by the MS promotion of metastable lipoplexes that may present regions of exposed pDNA, which will act as packing defects and facilitate destabilization. According to the results obtained by the different techniques, a theoretical model of DNA/lipid aggregation is proposed in Figure $\mathbf{5}$. This model summarizes the structural variations observed for the diverse pDNA/DODAB:MO formulations prepared by the different lipoplex preparation methods (OS $25{ }^{\circ} \mathrm{C}$, OS $50^{\circ} \mathrm{C}$, MS $25^{\circ} \mathrm{C}$ and MS $50^{\circ} \mathrm{C}$ ).

\subsection{One-Step/Multi-Step Preparation Methods Effect on 293T Cell Transfection Efficiency}

We have previously shown that MO-based lipoplexes prepared by $\mathrm{OS}$ procedure, at $25{ }^{\circ} \mathrm{C}$, efficiently transfect 293T cells [40]. It was also found that, with increasing $\mathrm{MO}$ content, the appearance of inverted non-lamellar structures at pDNA/DODAB:MO (1:1) lipoplexes results in higher pDNA compaction and higher lipoplex resistance to destabilizing agents [40]. As the temperature may also favor the inverted nonlamellar phases, we have decided to explore how temperature and preparation method affect the transfection efficiency of pDNA/DODAB:MO lipoplexes.

Figure 6 depicts the transfection efficiency of 293T cells incubated with the various lipoplexes tested.

For the three lipoplexes (pDNA/DODAB:MO 4:1, 2:1 and 1:1), OS preparation method promotes the higher transfection efficiencies.

The re-localization of positive charges at $50{ }^{\circ} \mathrm{C}$ in the lipoplex surface (irrespective of OS or MS addition) affects pDNA/DODAB:MO (4:1, 2:1 and 1:1) lipoplexes at different extents, because the initial structures of the liposomes are also different. DODAB enriched liposomes (DODAB:MO $(4: 1,2: 1))$ have a lamellar organization, where $\mathrm{MO}$ is mainly distributed in the lamellar phase of DODAB [48]. Encapsulation of pDNA will maintain the lamellar phase of DODAB:MO $(4: 1$ and 2:1), predominantly forming lipoplexes with

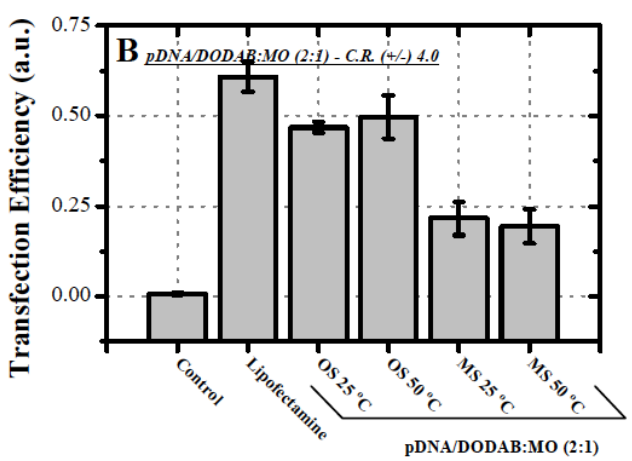

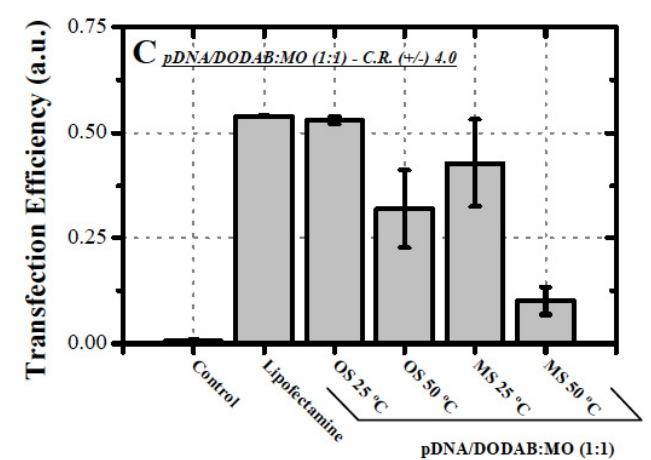

Figure 6: Reporter $\beta$-galactosidase activity $48 \mathrm{~h}$ after transfection of $293 \mathrm{~T}$ cells with different cationic lipoplexes (0.5 $\mu \mathrm{g}$ pDNA per well) prepared by different methods (OS $25^{\circ} \mathrm{C}$; OS $50^{\circ} \mathrm{C}$; MS $25^{\circ} \mathrm{C}$; and MS $50{ }^{\circ} \mathrm{C}$ ). Control: cells incubated with free pDNA. The mean (+/-) SD was obtained from three independent experiments. 
multilamellar structures, where the nucleic acid is located between the lipid membranes. In these pDNA/DODAB:MO $(4: 1$ and $2 ; 1)$ lipoplexes, the effect of charge re-localization is practically negligible in terms of transfection efficiency. In MO enriched liposomes (DODAB:MO (1:1) different vesicles with internal organization co-exist, and DODAB and $\mathrm{MO}$ self-assemble, respectively, into lamellar and nonlamellar phases [48]. The encapsulation of pDNA by DODAB:MO (1:1) will originate a DODAB-rich lamellar phase enclosing $\mathrm{MO}$ non-lamellar inverted phases, where DNA preferentially localizes. In these pDNA/DODAB:MO (1:1) lipoplexes, the effect of charge re-localization decreases transfection efficiency by 2 fold.

For lipoplexes with higher DODAB content (pDNA/DODAB:MO $(4: 1,2: 1)$, the OS procedure generally leads to better transfection efficiencies than the MS procedure. This might be explained by the higher DNA/lipid compaction achieved with the OS preparation method, which leads to smaller lipoplexes that are less destabilized by surface proteoglycans and consequently retain more pDNA.

The lipoplexes prepared with $\mathrm{MO}$ enriched liposomes (pDNA/DODAB:MO (1:1)) seem more dependent on the preparation procedure. This behavior is related to the different structure of this type of lipoplex at $25{ }^{\circ} \mathrm{C}$, and also to the effect of the temperature on promoting phase separation and promoting an increase in lamellar versus non-lamellar structures at $50^{\circ} \mathrm{C}$ (Supplementary Material 2). Lower temperatures imply more ordered lipid structures, which hinder the tight contact during DNA-lipid interaction essential for lipoplex production [17, 44].

The lower transfection efficiency obtained with lipoplexes prepared by MS procedure at $50^{\circ} \mathrm{C}$ may be also related with the packing defects of these lipoplexes structures, which are more sensible to destabilization by surface proteoglycans, consequently prematurely releasing their p-DNA content (Figure 4).

\section{CONCLUSIONS}

Optimization of the preparation method is essential to form lipoplexes with the best physicochemical properties to achieve high transfection efficiencies. This work shows that, at lower temperatures (under the lipid transition temperature), the MS addition of DODAB:MO cationic liposomes to pDNA is an adequate method for lipoplex preparation. However, above the lipid phase transition temperature, MS procedure promotes the formation of bigger lipoplexes with metastable structures. Furthermore, MS procedure forms less stable lipoplexes, able to easily release their nucleic acid content. All these characteristics explain the lower transfection efficiency obtained by lipoplexes prepared by MS procedure, regardless the MO content of the lipoplex. Therefore, OS addition of DODAB:MO liposomes to pDNA was found to be the best preparation method to form pDNA/DODAB:MO lipoplexes.

Our results also suggest that $\mathrm{MO}$ content must be tuned in the formulation in order to accomplish higher transfection efficiencies. The introduction of a third lipoid component, which may further influence the structural properties of the lipoplex formulations, is currently underway in order to improve the transfection efficiency of this non-viral vector.

\section{ACKNOWLEDGEMENTS}

We acknowledge Dra. Iva Pashkuleva from 3B's Research Group (AvePark Technology Park) for DLS and $\zeta$-potential measurements. This work has been funded by FEDER through POFC - COMPETE and by the Portuguese Foundation for Science and Technology (FCT) through projects PTDC/QUI/69795/ 2006 (I\&D grant), SFRH/BD/46968/2009 (PhD grant). Marlene Lucio holds a position of Researcher FCT with the reference IF/00498/2012. This work is protected by Portuguese National Patent $n^{0}$ 104158-Refa DP/01/ 2008/10900-31/12/2008 and International Patent submitted: PCT/IB2009/05361-PPI n40759/09, PEstOE/BIA/UI4050/2014 and PEst-C/FIS/UI0607/2013.

\section{ABBREVIATIONS}

$\begin{array}{ll}\text { DODAB } & =\text { dioctadecyldimethylammonium bromide } \\ \mathrm{MO} & =1 \text {-monooleoyl-rac-glycerol } \\ \mathrm{DLS} & =\text { dynamic light scattering } \\ \mathrm{ELS} & =\text { electrophoretic light scattering } \\ \zeta \text { potential } & =\text { zeta potential } \\ \text { cryo-TEM } & =\text { cryo-Transmission Electron Microscopy } \\ \text { EtBr } & =\text { Ethidium Bromide } \\ \mathrm{HEP} & =\text { heparin } \\ \mathrm{OS} & =\text { One step procedure for lipoplex }\end{array}$


MS $=\underset{\substack{\text { Multi-step procedure for lipoplex } \\ \text { preparation }}}{\text { m }}$

\section{SUPPLEMENTAL MATERIALS}

The supplemental materials can be downloaded from the journal website along with the article.

\section{REFERENCES}

[1] Gao X, Kim K, Liu D. Am Assoc Pharm Scient J 2007; 9: E92-E104.

[2] Huang L, Hung M, Wagner E. Nonviral Vectors for Gene Therapy - Part I ( $1^{\text {st }}$ Edition), $1^{\text {st }}$ ed., California (U.S.A.) 1999.

[3] Huang L, Hung M, Wagner E. Nonviral Vectors for Gene Therapy - Part II, $2^{\text {nd }}$ ed., California (U.S.A.) 2005.

[4] Huang L, Hung M, Wagner E. Nonviral Vectors for Gene Therapy - Part I ( $2^{\text {nd }}$ Edition), $2^{\text {nd }}$ ed., California (U.S.A.) 2005.

[5] Kiefer K, Clement J, Garidel P. Pharmaceut Res 2004; 21: 1009-1017. http://dx.doi.org/10.1023/B:PHAM.0000029291.62615.ec

[6] Taira K, Kataoka K, Niidome T. Non-viral Gene Therapy Gene Design and Delivery, $1^{\text {st }}$ ed., Tokyo (Japan) 2005.

[7] Uddin SN. Biotechnol Mol Biol Rev 2007; 2: 58-67.

[8] Bombelli C, Faggioli F, Luciani P, Mancini G, Sacco MG. J Med Chem 2005; 48: 5378-5382. http://dx.doi.org/10.1021/jm050477r

[9] Camilleri P, Kremer A, Edwards AJ, et al. Chem Commun 2000; 31: 1253-1254. http://dx.doi.org/10.1039/b001742f

[10] Kirby AJ, Camilleri P, Engberts JBFN, et al. Angew Chem Int Ed 2003; 42: 1448-1457. http://dx.doi.org/10.1002/anie.200201597

[11] Sekhon BS. Resonance 2004; 9: 42-49. http://dx.doi.org/10.1007/BF02834987

[12] Dias R, Lindman B. DNA Interactions with Polymers and Surfactants, $1^{\text {st }}$ ed., Hoboken (USA) 2008.

[13] Findeis MA. Nonviral Vectors for Gene Therapy - Methods and Protocols, $1^{\text {st }}$ ed., New Jersey (U.S.A.) 2001.

[14] Templeton NS. Gene and Cell Therapy: Therapeutic Mechanisms and Strategies, $2^{\text {nd }}$ ed., New York (U.S.A.) 2005.

[15] Benns JM, Choi J, Mahato RI, Park J, Kim SW. Bioconjug Chem 2000; 11: 637-645 http://dx.doi.org/10.1021/bc0000177

[16] Sakaguchi N, Kojima C, Harada A, Koiwai K, Kono K. Biomaterials 2008; 29: 4029-4036. http://dx.doi.org/10.1016/j.biomaterials.2008.06.006

[17] Wasungu L, Scarzello M, Dam GV, et al. J Mol Med 2006; 84: 774-784. http://dx.doi.org/10.1007/s00109-006-0067-z

[18] Rosa M, Penacho N, Simões S, Lima MCP, Lindman B, Graça-Miguel M. Mol Membr Biol 2008; 25: 23-34. http://dx.doi.org/10.1080/09687680701499451

[19] Yang P, Singh J, Wettig S, Foldvari M, Verrall RE, Badea I. Eur J Pharm Biopharm 2010; 75: 311-320. http://dx.doi.org/10.1016/j.ejpb.2010.04.007

[20] Hui SW, Langner M, Zhao Y, Ross P, Hurley E, Chan K. Biophys J 1996; 71: 590-599. http://dx.doi.org/10.1016/S0006-3495(96)79309-8

[21] Xu L, Anchordoquy TJ. Biochim Biophys Acta 2008; 1778 : 2177-2181.

http://dx.doi.org/10.1016/j.bbamem.2008.04.009
[22] Zuhorn IS, Oberle V, Visser WH, et al. Biophys J 2002; 83: 2096-2108.

http://dx.doi.org/10.1016/S0006-3495(02)73970-2

[23] Gonçalves E, Debs RJ, Heath TD. Biophys J 2004; 86: 15541563.

http://dx.doi.org/10.1016/S0006-3495(04)74223-X

[24] Ahmad A, Evans HM, Ewert K, George CX, Samuel CE, Safinya CR. J Gene Med 2005; 7: 739-748.

http://dx.doi.org/10.1002/jgm.717

[25] Koynova R, MacDonald RC. Biochim Biophys Acta 2007; 1768: 2373-2382.

http://dx.doi.org/10.1016/j.bbamem.2007.04.026

[26] Felgner JH, Kumar R, Sridhar CN, et al. J Biol Chem 1994; 269: 2550-2561.

[27] Boussif O, Zanta MA, Behr JP. Gene Therapy 1996; 3: 10101017.

[28] Kennedy MT, Pozharski EV, Rakhmanova VA, MacDonald RC. Biophys J 2000; 78: 1620-1633. http://dx.doi.org/10.1016/S0006-3495(00)76714-2

[29] Zuidam NJ, Barenholz Y. Int J Pharm 1999; 183: 43-46. http://dx.doi.org/10.1016/S0378-5173(99)00041-1

[30] Kichler A, Zauner W, Ogris M, Wagner E. Gene Therapy 1998; 5: 855-860. http://dx.doi.org/10.1038/sj.gt.3300658

[31] Madeira C, Loura LMS, Prieto M, Fedorov A. BioMed Centra Biotechnol 2008; 8: 20(21)-20(29).

[32] Stephenson FH, Calculations for Molecular Biology and Biotechnology, $1^{\text {st }}$ ed., New York (USA) 2003.

[33] Barreleiro PCA, Lindman B. J Phys Chem B 2003; 107: 6208-6213. http://dx.doi.org/10.1021/jp0277107

[34] Wolfbeis OS. Fluorescence Spectroscopy in Biology Advanced Methods and their Applications to Membranes, Proteins, DNA and Cells, $1^{\text {st }}$ ed., Berlin (Germany) 2005.

[35] Silva JPN, Coutinho PJG, Oliveira MECDR. J Fluorescence 2008; 18: 555-562 http://dx.doi.org/10.1007/s10895-007-0299-5

[36] Feitosa E, Barreleiro PCA, Olofsson G. Chem Phys Lipids 2000; 105: 201-213. http://dx.doi.org/10.1016/S0009-3084(00)00127-4

[37] Briggs J, Chung H, Caffrey M. J de Physique II 1996; 6: 723 751.

http://dx.doi.org/10.1051/jp2:1996208

[38] Lipowsky R, Sackmann E. Structure and Dynamics of Membranes, $2^{\text {nd }}$ ed., Amsterdam (Netherlands) 2004.

[39] Silva JPN, Coutinho PJG, Oliveira MECDR. J Photochem Photobiol A: Chem 2009; 203: 32-39. http://dx.doi.org/10.1016/j.jphotochem.2008.12.016

[40] Silva JPN, Oliveira ACN, Casal MPPA, et al. Biochim Biophys Acta 2011; 1808: 2440-2449. http://dx.doi.org/10.1016/j.bbamem.2011.07.002

[41] Real-Oliveira MECD, Silva JPN, Coutinho PJG, Coutinho OMFP, Gomes AFC, Casal MPPA. Aplicação da Monooleína como Novo Lípido Adjuvante em Lipofecção, in: I.N.d.P. Industrial (Ed.), Portuguese Patent n. PT104158 2010; pp. 127.

[42] Real-Oliveira MECD, Silva JPN, Coutinho PJG, Coutinho OMFP, Gomes AFC, Casal MPPA. Use of Monoolein as a New Auxiliary Lipid in Lipofection, in: W.I.P. Organization (Ed.), International Patent n. WO2010/020935 A2 2010; pp. 1-27.

[43] Ma B, Zhang S, Jiang H, Zhao B, Lv H. J Control Release 2007; 123: 184-194.

http://dx.doi.org/10.1016/j.jconrel.2007.08.022

[44] Hirsch-Lerner D, Barenholz Y. Biochim Biophys Acta 1999; 1461: 47-57.

http://dx.doi.org/10.1016/S0005-2736(99)00145-5 
[45] Rakhmanova VA, Pozharski EV, MacDonald RC. J Membr Biol 2004; 200: 35-45.

http://dx.doi.org/10.1007/s00232-004-0689-4

[46] Silva JPN, Oliveira ACN, Lúcio M, Gomes AC, Coutinho PJG, Oliveira MECDR. Tunable pDNA/DODAB:MO lipoplexes: The effect of Incubation Temperature on pDNA/DODAB:MO Lipoplexes Structure and Transfection Efficiency, (submitted manuscript) 2014.
[47] Ewert KK, Ahmad A, Evans HM, Safinya CR. Expert Opin Biol Therapy 2005; 5: 33-53.

http://dx.doi.org/10.1517/14712598.5.1.33

[48] Oliveira IMSC, Silva JPN, Feitosa E, Marques EF, Castanheira EMS, Oliveira MECDR. J Colloid Interf Sci 2012; 374: 206-217.

http://dx.doi.org/10.1016/j.jcis.2012.01.053 